\title{
PENDAMPINGAN PENGEMBANGAN KARAKTER WIRAUSAHA MELALUI KEGIATAN PRODUKSI PUPUK KOMPOS DARI LIMBAH RUMAH TANGGA DI KOTA SEMARANG
}

\author{
Hana Netti Purasani ${ }^{1}$, Inaya Sari Melati ${ }^{2}$, Wisudani Rahmaningtyas ${ }^{3}$ \\ Program Studi Pendidikan Ekonomi, Fakultas Ekonomi \\ Universitas Negeri Semarang \\ Email: hana@mail.unnes.ac.id
}

\begin{abstract}
The objective of this service activity is first, instilling the character of conservation through composting for students in Kalisegoro Elementary School. The second objective is to create a set of productive behavior and entrepreneurial spirit from the creation of compost which has high economic value. The method of implementing community service activities is carried out with training that produces skills, lecture methods, question and answer, discussion, simulation and mentoring. The strategic steps are: (1) Students and teachers will be given insight into the benefits of processing waste into organic compost, (2) Students and teachers will be given training in making organic compost from household waste, (3) Discussion sessions and questions answer by giving students and teachers the opportunity to ask questions regarding the making of organic compost fertilizer, (4) Providing assistance to students and teachers in organic compost production activities, and (5) Evaluating the results of the service activities that have been carried out. The next plan is training in marketing organic compost fertilizer.
\end{abstract}

Keywords: Conservation, Production, Compost, Organic Compost

\begin{abstract}
Abstrak. Tujuan kegiatan pengabdian ini adalah pertama,menanamkan karakter konservasi melalui pembuatan kompos kepada siswa-siswi di SD Negeri Kalisegoro. Tujuan kedua adalah menciptakan mindset perilaku produktif dan semangat berwirausaha dari adanya pembuatan pupuk kompos yang memiliki nilai ekonomi tinggi.Metode pelaksanaan kegiatan pengabdian kepada masyarakat ini dilakukan denganpelatihan yang menghasilkan keterampilan,metode ceramah, tanya jawab, diskusi, simulasi serta pendampingan. Adapun langkah strategis yaitu: (1) Peserta didik dan guru akan diberikan wawasan tentang manfaat pengolahan limbah menjadi pupuk kompos organik, (2) Peserta didik dan guru akan diberikan pelatihan pembuatan pupuk kompos organik dari limbah rumah tangga, (3) Sesi diskusi dan tanya jawab dengan memberikan kesempatan kepada peserta didik dan guru untuk bertanya terkait pembuatan pupuk kompos organik, (4) Melakukan pendampingan kepada peserta didik dan guru dalam kegiatan produksi pupuk kompos organik, dan (5) Evaluasi hasil dari kegiatan pengabdian yang telah dilakukan. Rencana tahapan berikutnya adalah pelatihan pemasaran pupuk kompos organik.
\end{abstract}

Kata Kunci: Konservasi, Produksi, Pupuk Kompos, Pupuk Kompos Organik

\section{PENDAHULUAN}

Di era globalisasi sangat diperlukan pendidikan karakter sejak dini. Uno, H. B. dan Mohamad, N, (2011) mengemukakan bahwa menyadarkan masyarakat yang sudah terlanjur kurang memahami arti kualitas lingkungan untuk kelestarian umat manusia sulit dilakukan. Sementara itu, Siswa usia Sekolah Dasar memiliki potensi untuk proses penanaman karakter karena memiliki kecenderungan rasa ingin tahu yang lebih tinggi. Hal ini tentu menjadi modal awal dalam proses pembelajaran (Ameliah, 2016).

Salah satu karakter yang tidak kalah penting untuk di tanamakan pada diri peserta didik sejak dini ialah sikap peduli terhadap lingkungan. Nilai karakter tersebut berupa sikap dan tindakan yang selalu berupaya mencegah kerusakan pada lingkungan alam sekitarnya (Asmani, 2013; Fadlillah, M. dan Khorida, L. M, 2013). Ridlo dan Irsadi (2012) menemukan bahwa karakter konservasi dapat dimulai dari hal yang kecil yang terjadi selama proses pembelajaran. Hal ini didukung oleh pendapat Wadhwani (2012) bahwa pembelajaran kewirausahaan harus menerapkan metode kreatif dan inovatif. Senada dengan pendapat Wadhwani, Kasmir (2006: 21)mengungkapkan bahwa kewirausahaan sebagai kemampuan dalam menciptakan memerlukan adanya kreativitas dan 
inovasi yang terus menerus untuk menemukan sesuatu yang berbeda.

Karakter dapat diwujudkan melalui sosialisasi yang dilakukan dengan tepat sasaran. Penanaman nilai karakter konservasi yang berkala dapat meningkatkan kecintaan anak kepada lingkungan di sekitarnya. Kepekaan dan rasa peduli juga dapat dilatih sejak dini melalui kegiatan konservasi lingkungan.

Selain karakter konservasi, semangat berwirausaha juga sangat penting untuk ditanamkan sejak dini pada peserta didik di tingkat Sekolah Dasar (SD). Karakter wirausaha menimbulkan semangat kerja, kreativitas, disiplin, inovatif, gigih, kerja tidak mudah putus asa yang merupakan karakteristik jiwa unggul yang diperlukan di bidang apa saja (Sukanti, Baswedan, dan Isroah: 2011). Smith, Sardeshmukh, dan Comb (2015) menguatkan

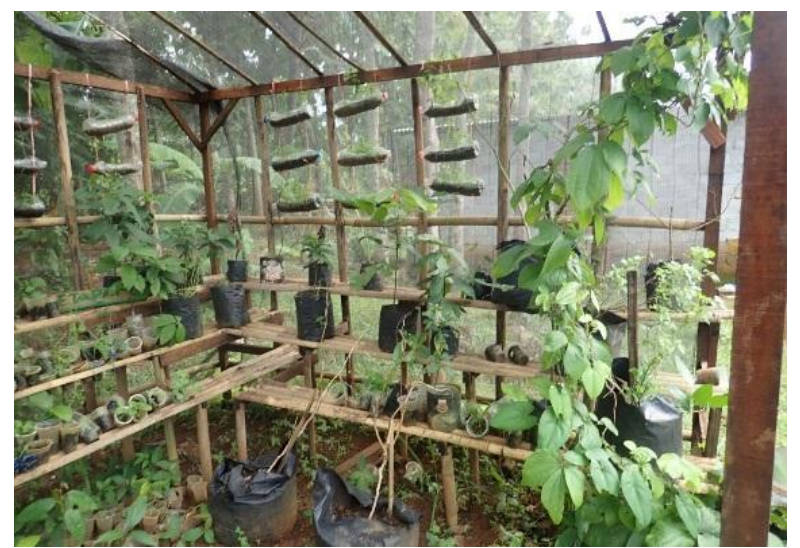

Gambar 1. Kebun Bibit Sekolah

Di sisi lain, kegiatan pembuatan pupuk kompos organik sebenarnya dapat dijadikan teknik untuk mengembangkan karakter wirausaha pada anak-anak. Pembentukan karakter wirausaha dapat dilakukan dengan cara mengenalkan peserta didik pada kegiatan meningkatkan nilai suatu barang atau disebut dengan kegiatan produksi. Limbah rumah tangga yang tidak terpakai dan dibuang dapat disulap menjadi pupuk kompos organik yang memiliki nilai ekonomi sekaligus membantu mengurangi permasalahan sampah. Kendala yang dihadapi untuk mewujudkan kegiatan ini adalah kurangnya kompetensi guru dalam menguasai teknik pembuatan pupuk kompos dari limbah rumah tangga. Oleh karena itu perlu adanya pendampingan berkala agar dapat menanamkan hasil penelitian tersebut dengan menyatakan bahwa kreatifitas memiliki pengaruh langsung dan positif terhadap minat berwirausaha. Tumbuhnya karakteristik wirausaha sangat ditentukan oleh pendidikan sejak dini yang akan merupakan landasan yang kokoh dan kuat.

SD Negeri Kalisegoro merupakan salah satu sekolah dasar yang memiliki perhatian lebih di bidang adiwiyata. Penanaman nilai-nilai konservasi pada siswa diterapkan di sekolah ini mulai beberapa tahun terakhir. Semangat konservasi di SD Kalisegoro sangat potensial untuk membentuk karakter kewirausahaan peserta didik sejak dini. SD Negeri Kalisegoro memiliki peralatan dan lahan untuk pembuatan kompos padat maupun cair. Namun pada praktiknya, pembuatan pupuk kompos tersebut hanya berjalan beberapa minggu di awal penilaian keikutsertaan lomba adiwiyata.

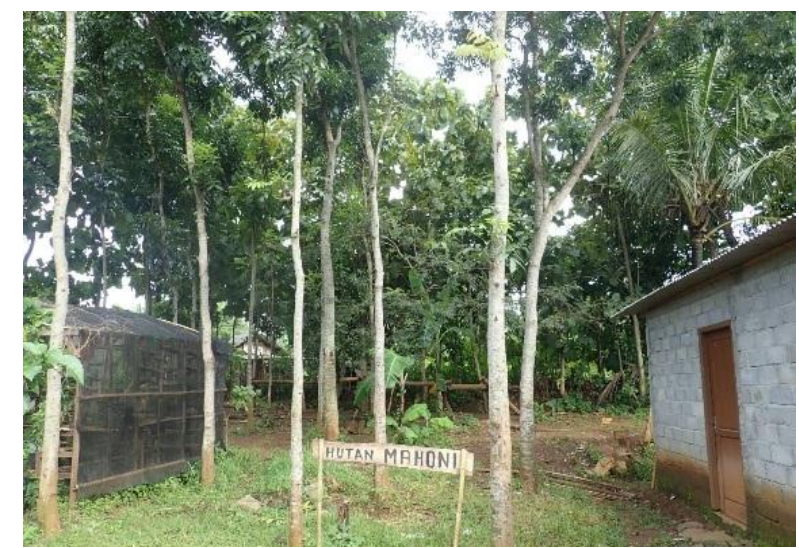

Gambar 2. Hutan Mahoni Sekolah

nilai karakter konservasi dan sekaligus kewirausahaan kepada peserta didik mulai dari sejak dini. Hal ini sesuai dengan hasil penelitian yang menekankan pentingnya client-mentor matchingdalam keberhasilan pembimbingan (Sulivan, 2000; Cope dan Watts, 2003).

Pendidikan dan latihan, mentoring dan belajar dari pengalaman merupakan faktor pembentuk pembelajaran kewirausahaan yang signifikan. Hal ini sesuai dengan pendapat beberapa ahli tentang pembelajaran wirausaha (Rae, 2000; Minniti dan Bygrave, 2001), proses pendidikan dan pelatihan (Ulrich dan Cole, 1987; Gibb, 1997;) maupun pembelajaran wirausaha dari pengalaman (Henderson, 1993; Rae, 2000; Cope dan Watts, 2003). Pembelajaran dapat dipandang sebagai proses perubahan dan 
pembentukan pengetahuan, keterampilan, sikap dan kemampuan seorang wirausahawan, baik melalui pendidikan, pelatihan, mentoring,ataupun pengalaman.

Pupuk kompos memiliki manfaat yang sangat baik untuk kesuburan tanaman. Selain kegunaannya yang ramah lingkungan pembuatan pupuk kompos juga dapat mengurangi sampah organik yang kurang banyak dimanfaatkan. SD Negeri Kalisegoro memiliki lahan yang cukup luas dengan banyak pohon jati di sekitar halaman belakang sekolah. Banyak daun kering yang berguguran di area tersebut. Sekolah ini juga telah memiliki mesin pencacah daun yang kurang dimaksimalkan penggunaannya. Siswa di sekolah ini perlu diarahkan untuk andil dalam pembuatan

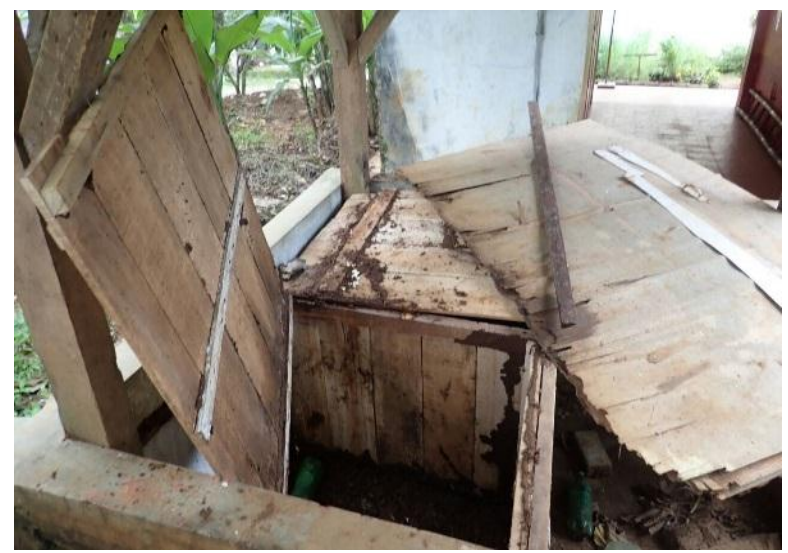

Gambar 3. Tempat Pembuatan Pupuk Padat yang Terbengkalai

Kondisi siswa di SD Negeri Kalisegoro hampir rata-rata hanya kelas 4,5 dan 6 yang pernah mengikuti pembelajaran praktik langsung membuat kompos. Sedangkan kaderisasi untuk menanamkan karakter konservasi terhadap siswa harus dilaksanakan secara berkala dan berkelanjutan. Hal tersebut dimaksudkan agar rasa kepekaan dan peduli lingkungan muncul dalam diri siswa dan mampu untuk mempraktikkan di lingkungan sekitarnya. Jika pemanfaatan lahan dan sarana prasarana kurang dimanfaatkan sebagai bahan pembelajaran siswa maka untuk menyiapkan siswa yang mampu berdaya saing dan berkarakter konservasi tidak akan terealisasikan dengan mudah. Perlu adanya penanaman karakter konservasi secara berkala dan berkelanjutan untuk menghasilkan generasi penerus bangsa yang peduli lingkungan dan pupuk kompos agar dapat meningkatkan pengetahuan tentang lingkungan di sekitarnya. Pembuatan kompos yang membutuhkan bahanbahan organik yaitu kotoran ternak, dedaunan kering, air kencing ternak, dedak kasar dan abu dapur. Di area belakang sekolah ada beberapa lahan yang di tanami sayuran dan buah. Terdapat pula rumah bibit yang kurang sesuai dengan fungsinnya. Area yang cukup luas kurang didukung dengan manajerial yang matang dan berkelanjutan sehingga konsep yang sudah dijalankan berjalan di tempat tanpa adanya pembaharuan yang mampu menggerakkan kembali kegiatan cinta lingkungan yang ada di SD Negeri Kalisegoro ini.

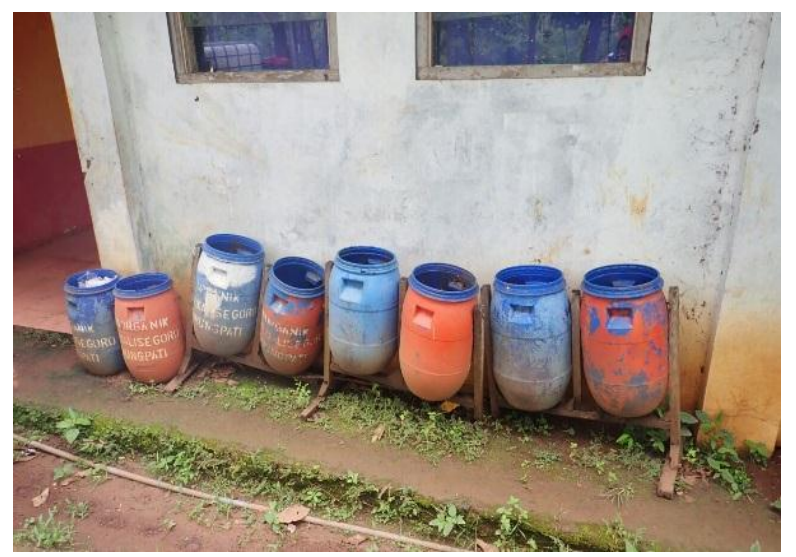

Gambar 4. Tempat Hasil Cincang Sampah yang Tidak Digunakan

memiliki kepekaan yang tinggi terhadap lingkungan di sekitarnya.

Konsep penanaman nilai konservasi melalui pembuatan kompos adalah dengan mengajarkan pada peserta didik sekolah dasar untuk memiliki pengetahuan bahwa bahan-bahan yang ada disekitar mereka memiliki manfaat yang tinggi. Bahan yang ada seperti kotoran ternak, dedaunan kering, air kencing ternak, dedak kasar dan abu dapur dapat memiliki kegunaan lebih. Selain itu pemanfaatan dari pupuk kompos juga dapat dijadikan sebagai pupuk untuk digunakan di lahan sekolah untuk membantu menyuburkan tanaman. Konsep inilah yang coba dikembangkan dengan rutin dan berkala agar dapat berguna bagi peningkatan kualitas siswa. Peningkatan dapat diperoleh dari segi pengetahuan, penanaman nilai-nilai karakter konservasi yaitu mencintai lingkungan dan 
kreatif dalam melihat kondisi di lapangan serta mampu membuatnya menjadi suatu peluang. Selain dari segi konservasi, pembuatan pupuk kompos organik ini juga berpotensi untuk mengembangkan jiwa kewirausahaan. Pembuatan pupuk kompos organik tersebut termasuk kegiatan produksi dengan pemanfaatan sumber daya alam yang kurang memiliki nilai menjadi memiliki nilai ekonomi yang tinggi.

SD Negeri Kalisegoro berpeluang besar mencetak peserta didik yang berkarakter wirausaha dan peduli lingkungan dengan adanya lahan yang mendukung serta beberapa sarana prasarana pembuatan pupuk kompos yang telah ada. Adapun bentuk permasalahan yang dihadapi secara umum adalah kurangnya kemampuan di tingkat manajerial yaitu belum dimilikinya pengetahuan tentang bagaimana cara pengembangan pembuatan pupuk kompos oleh tenaga pendidik dan belum adanya kegiatan rutin yang mampu membuat praktik pembuatan kompos secara berkala agar dapat berkelanjutan dan tidak mati suri dengan adanya kegiatan yang rutin dan tata kelola yang jelas. Pengabdian masyarakat perlu untuk dilakukan guna mengoptimalkan kembali potensi peningkatan karakter konservasi melalui pembuatan pupuk kompos di SD Negeri Kalisegoro

Berdasarkan identifikasi

diatas, dirumuskan masalah sebagai berikut.

1. Bagaimana pemantapan penanaman karakter konservasi melalui pembuatan pupuk kompos di SD Negeri Kalisegoro?

2. Bagaimana pembentukan mindset perilaku produktif wirausaha melalui pembuatan pupuk kompos di SD Negeri Kalisegoro?

\section{METODE PELAKSANAAN}

Kegiatan pengabdian dilakukan dengan metode sosialisasi, pendampingan, dan simulasi melalui beberapa langkah sebagai berikut.

1. Peserta didik dan pengajar SD Negeri Kalisegoro akan diberikan wawasan tentang pembuatan pupuk kompos
2. Pengajar SD Negeri Kalisegoro diberikan pengetahuan dan pemahaman kembali untuk mengoptimalkan potensi yang dimiliki sekolah dalam pembuatan pupuk kompos untuk menanamkan karakter wirausaha sekaligus karakter konservasi pada siswa

3. Memberikan gambaran dan simulasi pembuatan pupuk kompos dengan mengoptimalkan sarana prasarana yang ada

4. Melakukan pendampingan kepada pengajar untuk mengembangkan pembuatan kompos sebagai media untuk menanamkan karakter konservasi pada peserta didik

5. Evaluasi Kegiatan

\section{HASIL DAN PEMBAHASAN}

Sebelum melaksanakan pengabdian, tim pengabdian melakukan koordinasi dengan Kepala Sekolah SDN Kalisegoro untuk membahas pengaktifan kembali fungsi rumah bibit, rumah kompos dan rumah pilah sampah sebagai ruang belajar siswa dalam proses pembelajaran cinta lingkungan. Kegiatan ini dihadiri oleh Kepala Sekolah dan Wakil Kepala Sekolah Bidang Kesiswaan SDN Kalisegoro dan seluruh anggota tim pengabdian Fakultas Ekonomi UNNES pada hari Sabtu, 8 September 2018 di kantor Kepala Sekolah SDN Kalisegoro pada pukul 09.00 WIB.

Hasil dari pengabdian di SDN Kalisegoro adalah pengaktifan kembali fungsi rumah bibit, rumah kompos dan rumah pilah sampah sebagai ruang belajar siswa dalam proses pembelajaran cinta lingkungan. Rumah kompos yang mulanya terbengkalai dan tidak digunakan kini mulai aktif kembali penggunaannya oleh siswa dan pendampingan dari guru serta dukungan dari mitra tim pengabdian. Rumah kompos dibersihkan dan ditata kembali sesuai dengan funsi penggunaannya. 


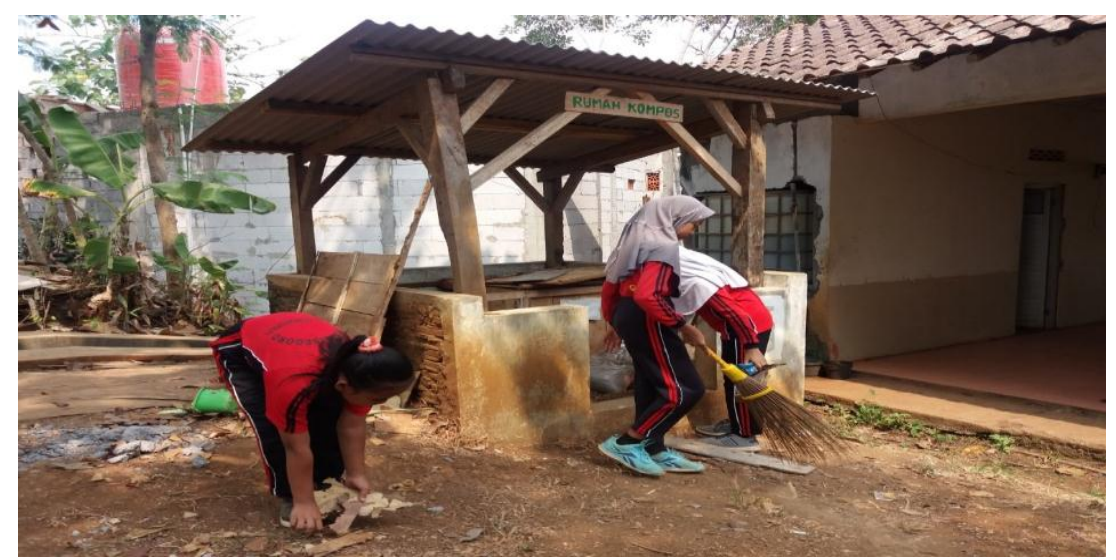

Gambar 5. Pembersihan Rumah Kompos oleh siswa SDN Kalisegoro

Tempat pembuatan kompos telah berfungsi kembali. Dua bagian pada tempat pengolahan kompos padat telah di gunakan sebagai satu sisi untuk pengolahan kompos dan sisi kedua untuk penyimpanan kompos yang telah jadi. Sampah disekitar sekolah dari hasil pilah sampah terutama dedaunan kering dihaluskan dengan mesin yang telah dimiliki sekolah. Dengan adanya pengabdian ini pendampingan siswa untuk menggunakan mesin pencacah daun hingga pengolahan sampah menjadi kompos padat maupun cair lebih terorganisir dan berkelanjutan.

Rumah kompos tidak hanya sebagai tempat pengolahan kompos padat akan tetapi melalui pengabdian ini pembuatan kompos cair juga diaktifkan lagi sehingga mampu memberikan pembelajaran lebih bagi siswa-siswi SDN Kalisegoro. Bak tempat pembuatan kompos cair dibenahi kembali sehingga dapat kembali berfunsi dengan baik. Fungsi rumah kompos yang produktif telah mampu mengatasi sampah organic yang ada di sekitar sekolah untuk diolah menjadi pupuk. Pupuk atau kompos hasil olahan siswa ini kemudian di manfaatkan untuk pupuk tanaman sayuran, buah-buahan serta obat-obatan yang ada di sekitar area sekolah.

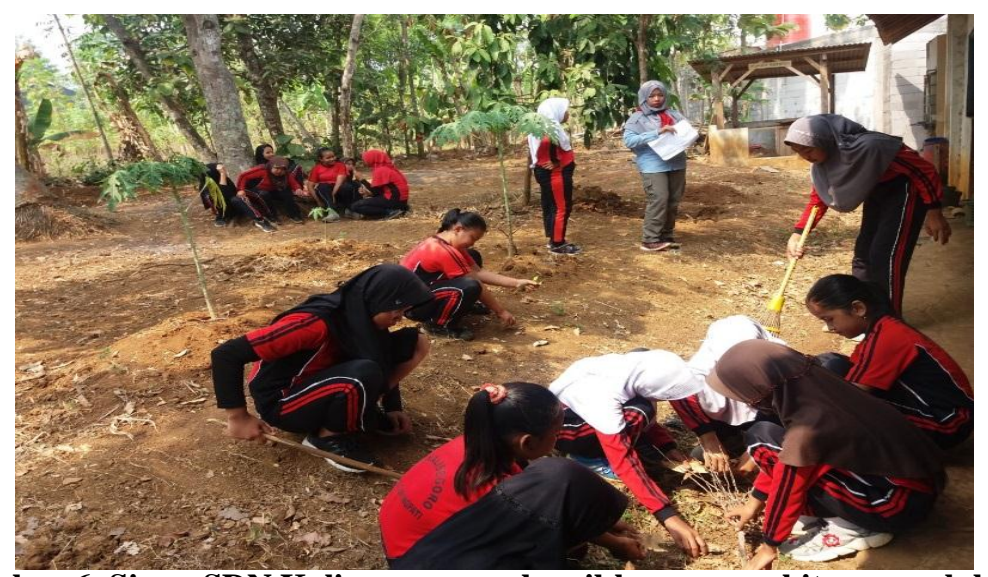

Gambar 6. Siswa SDN Kalisegoro membersihkan area sekitar rumah bibit

Selain rumah kompos yang telah produktif menghasilkan pupuk untuk tanaman, rumah bibit yang ada di SDN Kalisegoro juga mengalami meningkatan yang signifikan. Bibit yang mulanya ditumbuhi rumput serta banyak yang layu, kini mulai tumbuh subur. Rak bibit sudah dibersihkan dari rumput liar yang dapat mengganggu pertumbuhan bibit tanaman. Bibit yang ditanam juga lebih bervariasi. Sehingga siswa lebih banyak mengenal jenis-jenis tanaman. Rumah bibit ditata ulang menjadi lebih tertata dan rapi. Penataan ini juga memperhatikan fungsi tumbuh kembang tanaman sehingga tepat dan efisien. 


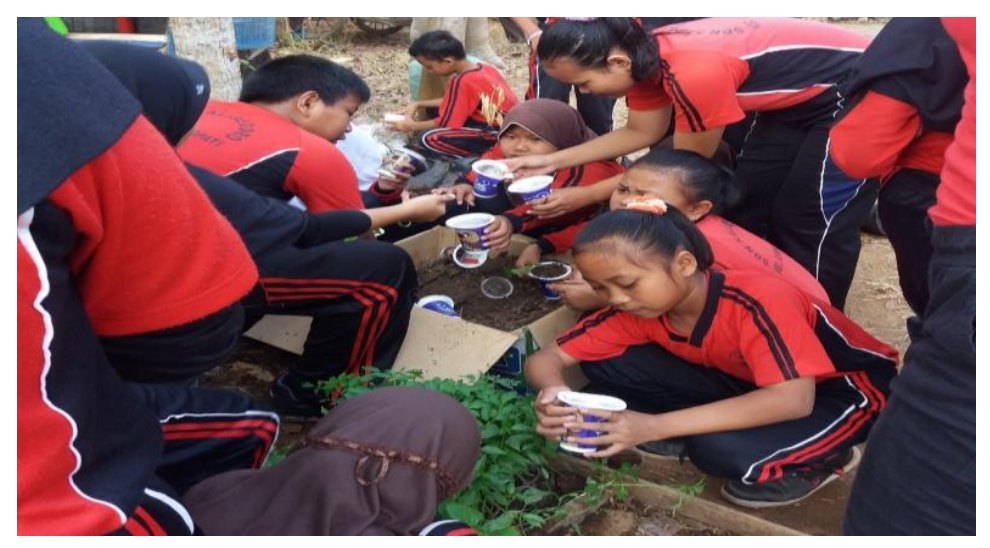

\section{Gambar 7. Siswa SDN Kalisegoro berlatih menanam bibit}

Rumah pilah sampah yang mulanya menjadi tempat sampah dimana berbagai sampah bercampur menjadi satu, kini penggunaannya diaktifkan kembali. Rumah sampah difungsikan kembali sebagai tempat memilah sampah. Pemberian label untuk penempatan sampah juga telah dibuat agar memudahkan siswa untuk memilah sampah. Pemilhan sampah dilakukan oleh siswa sehingga meningkatkan pengetahuan siswa tentang sampah yang dapat didaur ulang. Dari rumah pilah sampah ini telah terpilah sampah untuk dibuat kompos serta sampah yang dapat dimanfaatkan kembali.

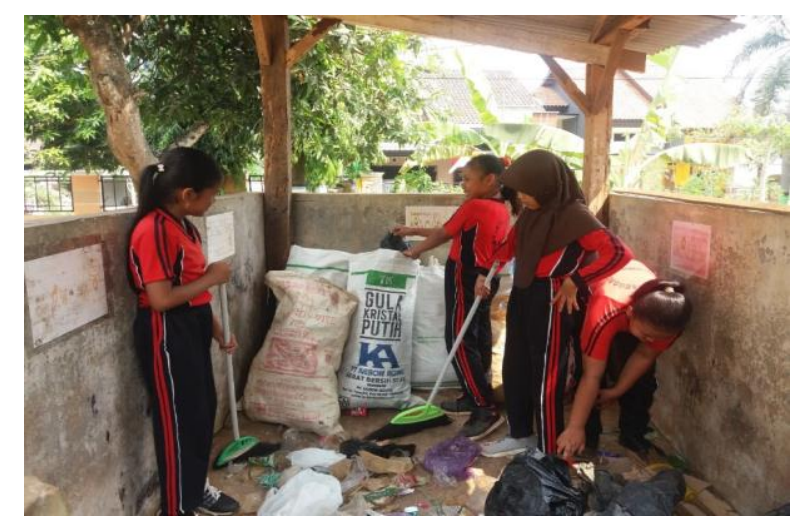

Gambar 8. Siswi SDN Kalisegoro Pembersihkan tempat pilah sampah

Secara keseluruhan pengabdian di SDN Kalisegoro berjalan dengan lancar. Sambutan dari Kepala Sekolah dan guru sangat antusias dengan adanya program ini dibuktikan dengan adanya gotong royong bersama untuk melakukan penanaman, pilah sampah dan pembuatan kompos. Siswa juga sangat aktif dan merespon dengan baik. Peran mitra pengabdian juga sangat membantu proses pengabdian ini. Oleh karena itu, diharapkan kegiatan ini tidak hanya mengaktifkan kembali proses pembelajaran cinta lingkungan akan tetapi dapat berlanjut hingga SDN Kalisegoro berperan aktif untuk mengajarkan pada siswa-siswinya tentang cinta lingkungan.

\section{SIMPULAN DAN SARAN}

Program pendampingan pengembangan karakter wirausaha meliputi perawatan rumah bibit, rumah kompos dan rumah pilah sampah dapat dilakukan secara rutin sehingga dapat terus produktif . Kegiatan rutin ini juga dapat menjadikan program sekolah yang digunakan untuk media belajar siswa. Program rutin perawatan rumah bibit, rumah kompos dan rumah pilah sampah dapat dikoordinir secara mandiri oleh sekolah sehingga dapat terlaksana secara berkelanjutan.

Produk yang dihasilkan dari rumah kompos dapat dijadikan untuk pupuk yang mampu memenuhi kebutuhan sekolah sehingga dapat menghemat perawatan tanaman yang ada di 
sekolah. Pupuk cair dan pupuk kompos ini dapat dikembangkan dan dapat mengatasi permasalahan sampah yang ada disekolah terutama sampah organik. Program perawatan bibit yang ada dirumah bibit dapat dirawat oleh siswa dan guru secara mandiri. Hasil dari tanaman yang ditanam dapat dimanfaatkan untuk olahan dan dapat dikonsumsi. Dari hasil pilah sampah dapat dikelola sampah dengan baik sehingga mampu menghasilkan sampah organik untuk bahan baku pembuatan pupuk dan sampah anorganik untuk di daur ulang untuk barang yang lebih fungsional dan berniali jual.

Dengan demikian pendampingan secara berkala perlu dilakukan guru kepada siswa untuk mengoptimalkan peluang dan perawatan serta pemanfaatan secara berkelanjutan dari rumah bibit, rumah kompos dan rumah pilah sampah yang mulai produktif kembali.

\section{DAFTAR PUSTAKA}

Ameliah, I.H., Munawaroh, M., \& Muchyidin, A. 2016. Pengaruh Keingintahuan dan Rasa Percaya Diri Siswa terhadap Hasil belajar Matematika Kelas VII MTs Negeri I Kota Cirebon. EduMa, 5 (1): 9-21. http://syekhnurjati.ac.id/jurnal/index.php/ eduma/article/view/598.

Asmani , Jamal Ma'mur. 2013. Buku Panduan Internalisassi Pendidikan Karakter di Sekolah. Jogjakarta: DIVA Press.

Cope, J., Watts, G., and Hulme, M. 2003. Ansoff's matrix, pain and gain: growth strategies and adaptive learning among small food producers, International Journal of Entrepreneurial Behavior and Research, Vol.4 (2), pp. 101-11.

Fadlillah, M \& Khorida, L. M. 2013. Pendidikan Karakter Anak Usia Dini: Konsep dan Aplikasinya dalam PAUD. Jogjakarta: Ar-Ruzz Media.

Gibb, A.A. 1997. Small firms' training and competitiveness. Building on the small business. International Small Business Journal, Vol. 15 (3), pp. 13-29.
Henderson, N. 1993. Action Learning: A Missing Link in Management Development. Personnel Review, Vol.22 (6), pp. 14-24.

Kasmir. 2006. Kewirausahaan. Jakarta: Raja Grafindo Persada.

Minniti, M., and Bygrave, W. 2001. A Dynamic Model of Entrepreneurial Learning. Entrepreneurship Theory and Practice. Spring.

Smith, RM; Sardeshmukh, SR; dan Combs, GM. 2015. Uderstanding Gender, Creativity, and Entrepreneurial Intentions. Diakses dari: $\quad$ www.emeraldinsight.com/00400912.htm pada 29 Maret 2017 pukul 10:57 WIB.

Sukanti; Baswedan, A.R.; \& Isroah. 2012. Peran Ibu dalam Menumbuhkan Jiwa Wirausaha Anak. Jurnal Pendidikan Akuntansi Indonesia, Vol. IX. No. 2, Hal. 79-91.

Sulivan, R. 2000. Entrepreneurial Learning and Mentoring. International Journal of Entrepreneurial Behavior \& Research. Vol. 6 (3), pp. 160-175.

Rae, D. 2000. Understanding entrepreneurial learning: A Question of How? International Journal of Entrepreneurial Behavior and Research, Vol. 6 (3), pp. 145-159.

Ridlo, S., \& Irsadi, A. 2012. Pengembangan Nilai Karakter KonservasiBerbasis Pembelajaran. Jurnal Penelitian Pendidikan. Vol. 29 Nomor 2. Hal. 145154.

Ulrich, T.A. and Cole, G. S. 1987. Toward MoreEffective Training of Future Entrepreneurs. Journal of Small Business Management. Vol. 25 (4). Pp. 32.39.

Uno, H. B. \& Mohamad, N. 2011. Belajar dengan Pendekatan PAILKEM. Jakarta : PT BumiAksara.

Wadhwani, D.R. 2012. How Entrepreneurship Forgot Capitalism: EntrepreneurshipTeaching and Research in Business Schools. Soc (2012) 49:223229. DOI 10.1007/s12115-012-9535-y 